\title{
DISCUSSION
}

\section{Shear wave velocity and stiffness of sand: the role of non-plastic fines}

\author{
J. YANG*, X. LIU*, M. M. RAHMAN†, R. LO†, M. GOUDARZY§ and T. SCHANZ§
}

\author{
Contribution by M. M. Rahman, R. Lo, M. Goudarzy \\ and T. Schanz
}

This discussion addresses the following issues related to the effects of fines content, $f_{\mathrm{c}}$, on $G_{0}$

(a) the exponential relation between $A$ and $f_{\mathrm{c}}$

(b) the relation between state parameter $\psi$ and $G_{0}$

(c) the relation between $e^{*}$ and $G_{0}$, noting the difference between $e_{\mathrm{s}}$ and $e^{*}$.

\section{Exponential relation between $\boldsymbol{A}$ and $\boldsymbol{f}_{\mathrm{c}}$}

The authors (Yang \& Liu, 2016), by using $c=2 \cdot 17$ for Toyoura sand (sub-round) with crushed silica fines in the empirical equation of Hardin and Black (1966), suggested that $A$ deceases with increasing $f_{\mathrm{c}}$ and can be presented by a simple exponential function of $f_{\mathrm{c}}$ (their equation (4)). However, the $A-f_{\mathrm{c}}$ relationship for a specific sand-fines mixture may not be applicable to another sand-fines mixture, as evident from the database of Rahman et al. (2012) and presented as Fig. 24 (together with the authors' data). Furthermore, the simple exponential relation as expressed in their equation (4) may not be always applicable - for example, it cannot simulate the shape of the experimental relationship of Yunlin sand.

\section{Relation between state parameter $\psi$ and $G_{0}$}

The authors proposed their equation (8) as reproduced below

$$
G_{0}=A_{\psi} \frac{(a-\psi)^{2}}{1+\psi}\left(\frac{\sigma^{\prime}}{p_{\mathrm{a}}}\right)^{m}
$$

where $A_{\psi}, a$ and $m$ are regression parameters and $\psi$ is the state parameter as defined by Been \& Jefferies (1985). However, Hsiao \& Phan (2016) examined $G_{0}$ and $\psi$ data for Kaohsiung city sand in Taiwan and did not find any correlation between them. Indeed, the incorporation of both $\psi$ and $\sigma^{\prime}$ into equation (10) means the stress state is not adequately captured by $\psi$ in the prediction of $G_{0}$. As equation (10) was obtained by replacement of $F(e)$ with $F(\psi)$ in Hardin's equation, and other elements of it, including $\sigma^{\prime}$, remain unchanged, the functioning of $\psi$ in equation (10) may be argued to be an 'adjusted' density state. Practically, it does not offer much advantage as more input information

\footnotetext{
* Department of Civil Engineering, The University of Hong Kong, Hong Kong.

$\dagger$ Natural and Built Environments Research Centre (NBERC) and School of Natural and Built Environments, University of South Australia, Mawson Lakes, SA, Australia.

\$ School of Engineering and Information Technology University of New South Wales, Canberra, Australia.

$\S$ Chair of Foundation Engineering, Soil and Rock Mechanics, Ruhr-Universität Bochum, Bochum, Germany.
}

(locations of CSLs for a range of $f_{\mathrm{c}}$ ) is required in equation (10), and $A_{\psi}$ is still soil type dependent. Whether the exponent $n=0.4$ and the constant $a=1.36$ in the authors' equation (9) are applicable to other sand-fines mixture is also yet to be investigated.

\section{Relation between $e^{*}$ and $G_{0}$}

The discussers would like first to point out the difference between two related parameters, $e_{\mathrm{s}}$ and $e^{*}$, as these are mixed up by the authors.

The concept of skeleton void ratio, $e_{\mathrm{s}}$, assumes that the fines behave as void space, and can be given by the equation below (Thevanayagam, 1998)

$$
e_{\mathrm{s}}=\frac{e+f_{\mathrm{c}}}{1-f_{\mathrm{c}}}
$$

Direct evidence, such as scanning electron microscopy in the early 1990s, revealed that a portion of fines contribute to force in the skeleton structure (Pitman et al., 1994); and this is particularly true as $f_{\mathrm{c}}$ increases. To account for such a mechanism, Thevanayagam et al. (2002) proposed the concept of equivalent granular void ratio, $e^{*}$, for $f_{\mathrm{c}}<f_{\text {thre }}$

$$
e^{*}=\frac{e+(1-b) f_{\mathrm{c}}}{1-(1-b) f_{\mathrm{c}}}
$$

where $b$ is the fraction of fines that take part in the skeleton force structure and $f_{\text {thre }}$ is the threshold fines content as defined in Thevanayagam et al. (2002). It is evident that $e_{\mathrm{s}} \neq e^{*}$. The authors appear to mix up $e_{\mathrm{s}}$ and $e^{*}$ by wrongly stating 'The above concept $\left[e_{\mathrm{s}}\right]$ was followed by Rahman et al. (2014) in formulating a constitutive model for sand-fines mixtures' (Yang \& Liu, 2016: p. 507).

Rahman et al. (2014) used $e^{*}$ in formulating the constitutive model. The $b$ parameter was predicted using the following semi-empirical equation (Rahman et al., 2008)

$$
b=\left\{1-\exp \left[-\mu \frac{\left(f_{\mathrm{c}} / f_{\text {thre }}\right)}{k}\right]\right\} \times\left(r \frac{f_{\mathrm{c}}}{f_{\text {thre }}}\right)^{r}
$$

where $r=(\chi)^{-1}=d_{50} / D_{10}, k=\left(1-r^{0 \cdot 25}\right)$. A large number of data sets (ten different host sands with many different $f_{\mathrm{c}}$ ) were examined to establish the values of $\mu$ and $f_{\text {thre }}$ (Rahman \& Lo, 2008) and it was concluded that

(a) $\mu=0.30$ is a suitable default value for non-angular sand and silt

(b) $f_{\text {thre }}$ can be predicted from grading properties by

$$
f_{\text {thre }}=0 \cdot 40\left[\frac{1}{1+\exp (0 \cdot 50-0 \cdot 13 \chi)}+\frac{1}{\chi}\right]
$$

It is evident that the relationship between $e_{\mathrm{s}}$ and $e^{*}$ is dependent on $f_{\mathrm{c}}$, and $b \rightarrow 0$ only if $f_{\mathrm{c}} \rightarrow 0$. Thus using $e_{\mathrm{s}}$, as attempted by the authors, to examine the influence of $f_{\mathrm{c}}$ may be fundamentally inconsistent. 


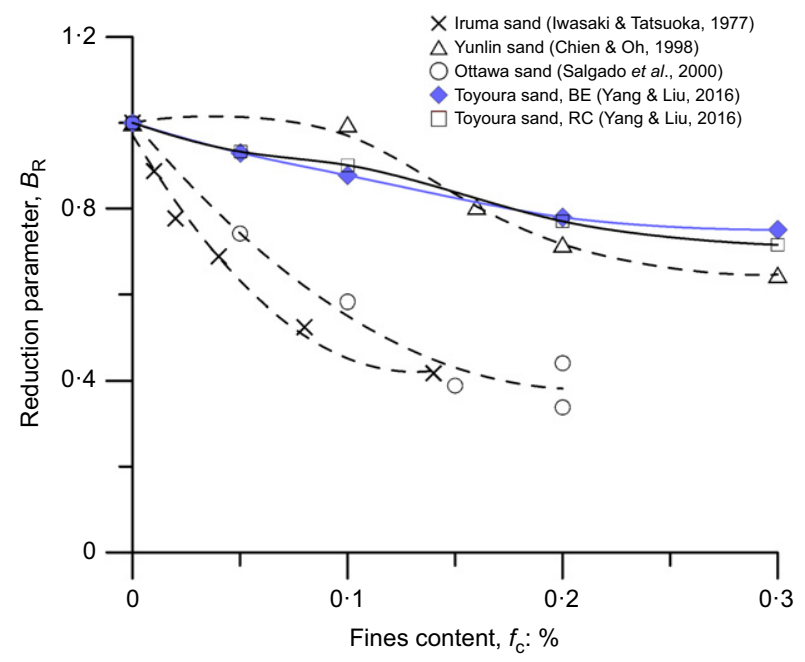

Fig. 24. Variation of parameter $\boldsymbol{A}$ in Hardin's equation for clean sand and sand with $f_{\mathrm{c}}$ (normalised by $\boldsymbol{A}$ for clean sand) (data after Iwasaki \& Tatsuoka, 1977; Chien \& Oh, 1998; Salgado et al., 2000; Yang \& Liu, 2016)

Rahman et al. (2014) proposed the following $e^{*}-G_{0}$ relationship, which is obtained by replacing $e$ with $e^{*}$ of Hardin's equation.

$$
G_{0}=A \frac{\left(2 \cdot 17-e^{*}\right)^{2}}{1+e^{*}}\left(\frac{\sigma^{\prime}}{p_{\mathrm{a}}}\right)^{n}
$$

where $A$ and $n$ are deduced from $G_{0}$ data for clean sand. As $b$ can be computed using equations (13) and (14), $e^{*}$ can be deduced from $e$ and thus $G_{0}$ can be predicted. Rahman et al. (2012) demonstrated that $G_{0}$ predicted in this manner agreed reasonably well with published data sets provided $f_{\mathrm{c}}<f_{\text {thre }}$. Recent work by Goudarzy et al. (2016) for Huston sand with $f_{\mathrm{c}}$ in the range of $0-0 \cdot 30$ also showed that $G_{0}$ is well predicted by equation (15) (and with $e^{*}$ calculated from the same methodology). Since $e^{*}$ can capture the effect of $f_{\mathrm{c}}$ in predicting $G_{0}$, and $e_{\mathrm{s}} \neq e^{*}$, it directly follows that the use of $e_{\mathrm{s}}$ in Hardin's equation will not be able to capture the effect of fines as demonstrated experimentally by the authors in their Fig. 15.

The discussers also attempted to evaluate equation (15) using the authors' data sets for Toyoura sand with fines derived from crushed silica. The bender element and resonant column data set for the host sand give $A=104$ and $n=0 \cdot 39$. However, the determination of $e^{*}$ is a challenge because the fines in the authors' study, being produced by a crushing process, is likely to be highly angular and thus the default value of $\mu=0.3$ is unlikely to be applicable. There is also one additional complication for using Hardin's equation: $c$ is neither $2 \cdot 17$ (for sub-round Toyoura sand) nor 2.97 (for angular, crushed fines), but somewhere in between and depending on $f_{\mathrm{c}}$. Thus, there is an intrinsic error in adopting $c=2 \cdot 17$. As a simplified process of dealing with these two challenges, $\mu$ was back-analysed by optimising the correlation between computed and experimental $G_{0}$ values using $f_{\mathrm{c}}=0 \cdot 30$ data points - that is, not all sand with fines data were used. This yields $\mu=2 \cdot 0$ for the calculation of $b$ and thus $e^{*}$. The $G_{0}$ values for $f_{\mathrm{c}}=0 \cdot 10$ and $0 \cdot 20$ can then be predicted using equation (15) and compared to experimental data. Good agreement is evident, as presented in Fig. 25.

\section{Authors' reply}

The first point raised by the discussers is about the exponential relationship between parameter $A$ and fines

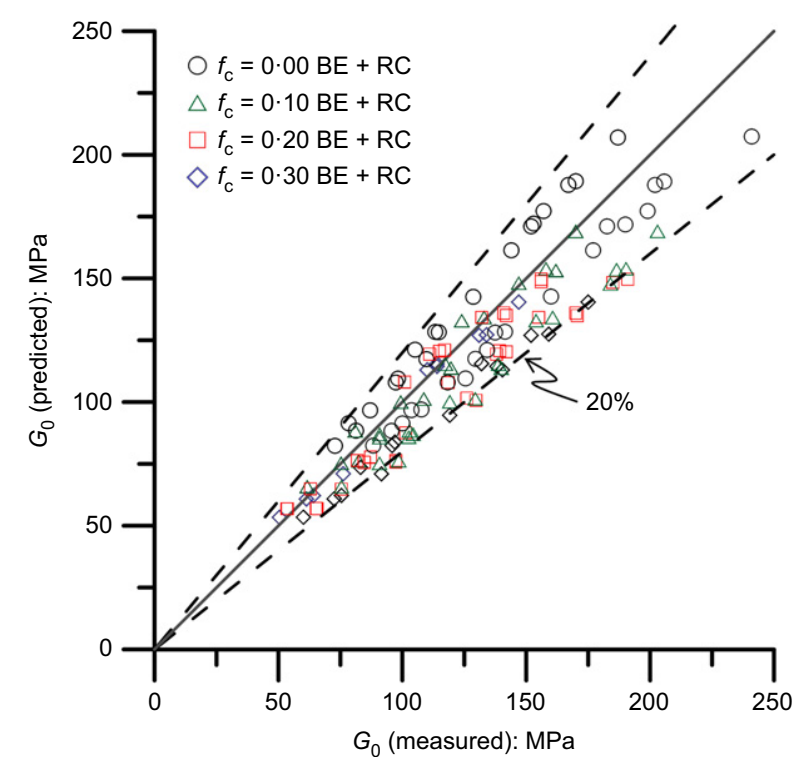

Fig. 25. Comparison between measured and predicted $G_{0}$ using $e^{*}$ in equation (15). BE, bender element; $\mathrm{RC}$, resonant column

content (FC) given in equation (4) of the paper. They argue that the relationship is not applicable to some other sandfines mixtures in the literature. This should not be a surprise because the relationship was established from experimental data on a specific sand-fines mixture and, hence, should be generally viewed as material dependent. That is to say, a relationship derived for a sand-fines mixture may not be applicable to another mixture unless these two mixtures share similar grain characteristics (e.g. mineralogy, grain size distribution, grain shape and so on). In particular, for the binary mixtures concerned here, the size ratio between coarse and fine grains is an important factor affecting the mechanical behaviour - which has been emphasised in the paper (Yang \& Liu, 2016: p. 511) and in an earlier paper by Yang and co-workers (Yang et al., 2015). Experimental evidence for the size disparity effect has also been shown in Fig. 22(a) of the paper, from which it is possible to see that reduction of $G_{0}$ with the addition of the crushed silica fines is more significant for Fujian sand $\left(D_{50}=397 \mu \mathrm{m}, C_{\mathrm{u}}=1.532\right)$ than for Toyoura sand $\left(D_{50}=216 \mu \mathrm{m}, C_{\mathrm{u}}=1 \cdot 392\right)$. For comparison, Fig. 26 here presents the variation of parameter

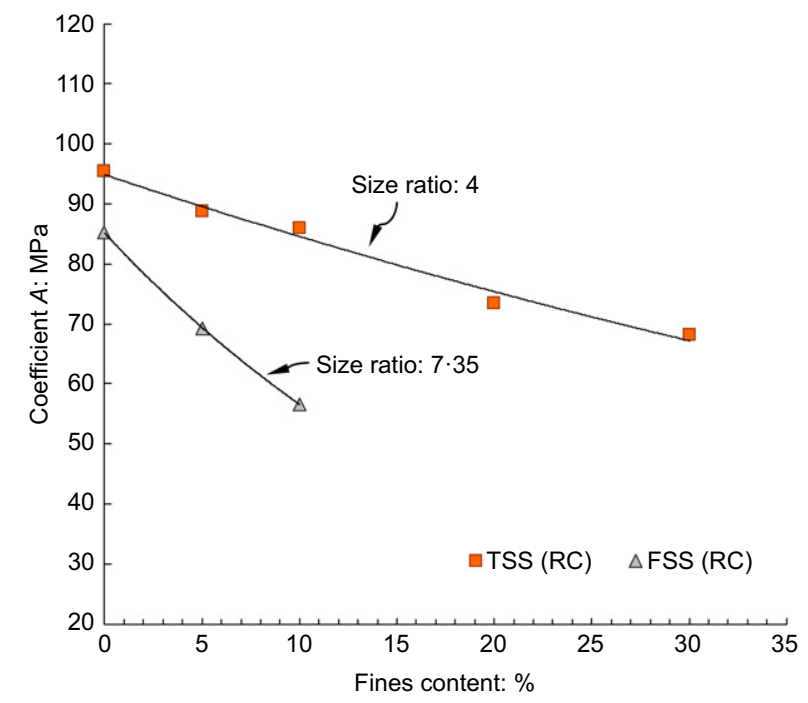

Fig. 26. Variation of parameter $A$ with fines content (resonant column (RC) test data) for Toyoura sand (TSS) and Fujian sand (FSS) 
$A$ with fines content for these two sands. If the size ratio is simply defined as the mean size of coarse particles (i.e. base sand) to the mean size of fines, then the mixture of Fujian sand and crushed silica fines has the ratio of 7.35 as compared with 4 for the mixture of Toyoura sand and crushed silica fines. The authors consider that the different trend lines exhibited by Ottawa sand and Iruma sand in Fig. 24 can be mainly attributed to different grain characteristics, particularly size ratios, if other testing conditions are comparable. Although different sand-fines mixtures exhibit different trends, exponential functions appear to be able to fit these data sets reasonably well, except for Yunlin sand. There is not sufficient information to allow evaluation of the tests of Chien \& Oh (1998) - for example, it is not clear whether the initial relative density used to compare the test results refers to the postconsolidation state or not - but the data point corresponding to the fines content of $10 \%$ is likely anomalous. Despite this, the data set for Yunlin sand does show a broad agreement with the other four data sets that $G_{0}$ tends to decrease with increasing the quantity of fines.

The second point raised in the discussion is about the relationship between $G_{0}$ and state parameter $\psi$ given in equation (8) of the paper. The discussers argue that both $\psi$ and $\sigma^{\prime}$ are incorporated in the relationship and the functioning of $\psi$ may be an adjusted density state. The authors do not agree with this argument. The state parameter has a sound physical meaning and has been widely recognised to be useful in characterising and modelling various aspects of the behaviour of sands (e.g. Been \& Jefferies, 1985; Wood et al., 1994; Li \& Dafalias, 2000; Yang \& Li, 2004). There is no particular reason why $\sigma^{\prime}$ should not be involved in the relationship. A rational and logical development of the relationship has been demonstrated through data interpretation in Figs 8, 20 and 21 of the paper. The necessity of involving $\sigma^{\prime}$ is evident from the four plots in Fig. 20, which correspond to four different effective confining stresses. In fact, the relationship in equation (8) provides some important insight into the common practice of using a normalised or corrected shear wave velocity $\left(V_{\mathrm{s} 1}\right)$, not the shear wave velocity $\left(V_{\mathrm{s}}\right)$ in liquefaction evaluation (e.g. Robertson et al., 1992; Andrus \& Stokoe, 2000). The normalised shear wave velocity is generally given by

$$
V_{\mathrm{s} 1}=V_{\mathrm{s}}\left(\frac{p_{\mathrm{a}}}{\sigma^{\prime}}\right)^{b}
$$

where $\sigma^{\prime}$ is the mean effective stress, $p_{\mathrm{a}}$ is the reference stress and $b$ is the stress exponent (a default value of $1 / 4$

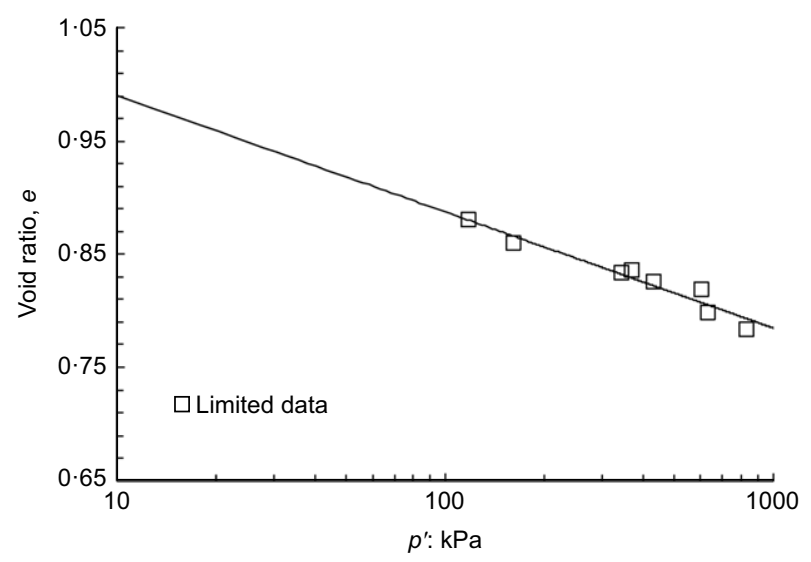

(a) is commonly used). Noting the fundamental relation as follows

$$
G_{0}=\rho V_{\mathrm{s}}^{2}
$$

equation (8) in the paper can be re-written as

$$
V_{\mathrm{s}}=\sqrt{\frac{A}{\rho} F(\psi)}\left(\frac{\sigma^{\prime}}{p_{\mathrm{a}}}\right)^{m / 2}=g(\psi)\left(\frac{\sigma^{\prime}}{p_{\mathrm{a}}}\right)^{m / 2}
$$

Letting $b=m / 2$, the following is then obtained

$$
V_{\mathrm{s} 1}=V_{\mathrm{s}}\left(\frac{p_{\mathrm{a}}}{\sigma^{\prime}}\right)^{b}=g(\psi)
$$

The above equation is fundamentally significant because it indicates that a relationship exists between the normalised shear wave velocity and the state parameter. The important implication is that the shear wave velocity can be used to evaluate the state parameter for both clean and silty sands in a unified way. Part of the work along this line has recently been reported in Yang et al. (2017), where direct measurements of $V_{\mathrm{s}}$ by means of bender elements were used for analysis, and the results are very encouraging.

Turning to the question of why the test data of Hsiao \& Phan (2016) do not show any correlation between $G_{0}$ and $\psi$, the authors do not have sufficient information to evaluate their data, but would like to make several important observations. First, the fines used in the tests were not non-plastic but with a certain degree of plasticity, and the threshold fines content determined was unusually high $(\sim 50 \%)$. Second, the critical states were determined from triaxial tests at rather low strain levels - whether critical states were reached at such strain levels is in doubt. Third, the critical state loci were represented by straight lines in the $e-\ln p^{\prime}$ plane, but it is now widely accepted that the critical state locus is a curved rather than a straight line (e.g. Verdugo \& Ishihara, 1996; Yang \& Wei, 2012); use of a straight critical state line in determination of the state parameter may introduce considerable errors in some situations. To make the point, Fig. 27(a) shows the critical state data for Toyoura sand mixed with $10 \%$ fines (TSS10), determined from a number of undrained triaxial tests, along with the trend line that best fits the data. The traditional linear representation apparently works well. Nevertheless, when a wider range of sand states is involved, inadequacy of the linear function becomes evident (Fig. 27(b)). Finally, and perhaps more importantly, Hsiao \& Phan (2016) simply plotted all $G_{0}$ values against $\psi$, without properly identifying and accounting for the effect of confining stress.

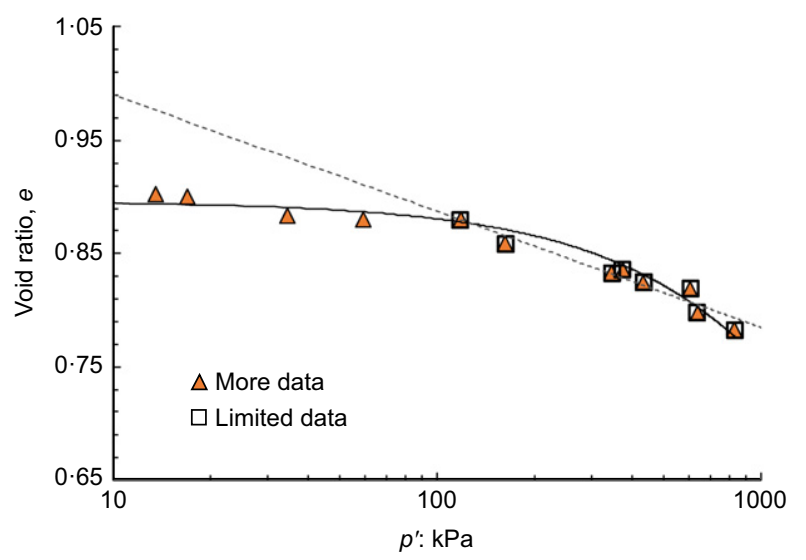

(b)

Fig. 27. Representation of critical state locus in compression space for Toyoura sand with $10 \%$ fines (TSS10): (a) a straight line on a semi-log scale with limited data; (b) a curved line on a semi-log scale with more data 
The final point raised in the discussion is on the relation between $G_{0}$ and the equivalent granular void ratio $\left(e^{*}\right)$. The authors are fully aware of the difference between the so-called skeleton void ratio $\left(e_{\mathrm{s}}\right)$ and $e^{*}$, but do not consider it is a fundamental difference. Rather, the skeleton void ratio can be regarded as a special case of the equivalent granular (or skeleton) void ratio by assuming $b=0$. Yang and his co-workers conducted an investigation into the rationale behind these concepts along with a careful evaluation of the two skeleton void ratios and the usual global void ratio (e) when applied to sand-fines mixtures. The main conclusion of that study is that the concept of the equivalent skeleton void ratio is logically inconsistent with its premise and does not fulfil the intent of providing a universal means for characterising the behaviour of silty sands. This is due to its lacking mechanisms to account for the inter-granular contacts, which are highly complex. Compared with $e_{\mathrm{s}}$ and $e^{*}$, the usual void ratio remains a simple and useful state variable suitable for the framework of critical state soil mechanics and for geotechnical applications. Readers can refer to Yang et al. (2015) for more details. In addition, Dai \& Yang (2013) and Dai et al. (2015) have provided some viewpoints from grain scale modelling.

\section{REFERENCES}

Andrus, R. \& Stokoe, K. H. (2000). Liquefaction resistance of soils from shear-wave velocity. J. Geotech. Geoenviron. Engng, ASCE 126, No. 11, 1015-1025.

Been, K. \& Jefferies, M. G. (1985). A state parameter for sands. Géotechnique 35, No. 2, 99-102, https://doi.org/10.1680/ geot.1985.35.2.99.

Chien, L. K. \& Oh, Y. N. (1998). Influence on the shear modulus and damping ratio of hydraulic reclaimed soil in West Taiwan. Int. J. Offshore Polar Engng 8, No. 3, 228-235.

Dai, B. \& Yang, J. (2013). On the physical meaning of equivalent skeleton void ratio for granular soil with fines. AIP Conference Proc. 1542, 257-260.

Dai, B., Yang, J. \& Luo, X. (2015). A numerical analysis of the shear behavior of granular soil with fines. Particuology 21, 160-172.

Goudarzy, M., Rahman, M. M., König, D. \& Schanz, T. (2016). Influence of non-plastic fines content on maximum shear modulus of granular materials. Soils Found. 56, No. 6, 973-983.

Hardin, B. O. \& Black, W. L. (1966). Sand stiffness under various triaxial stresses. J. Soil Mech. Found. Div. ASCE 92, No. SM2, $27-42$.

Hsiao, D. H. \& Phan, V. T. A. (2016). Evaluation of static and dynamic properties of sand-fines mixtures through the state and equivalent state parameters. Soil Dynamics Earthquake Engng 84, 134-144.
Iwasaki, T. \& Tatsuoka, F. (1977). Effects of grain size and grading on dynamic shear moduli of sands. Soils Found. 17, No. 3, $19-35$.

Li, X. S. \& Dafalias, Y. F. (2000). Dilatancy for cohesionless soils. Géotechnique 50, No. 4, 449-460, https://doi.org/10.1680/geot. 2000.50.4.449.

Pitman, T. D., Robertson, P. K. \& Sego, D. C. (1994). Influence of fines on the collapse of loose sands. Can. Geotech. J. 31, No. 5, 728-739.

Rahman, M. M. \& Lo, S. R. (2008). The prediction of equivalent granular steady state line of loose sand with fines. Geomech. Geoengng 3, No. 3, 179-190.

Rahman, M. M., Lo, S. R. \& Gnanendran, C. T. (2008). On equivalent granular void ratio and steady state behaviour of loose sand with fines. Can. Geotech. J. 45, No. 10, 1439-1455.

Rahman, M. M., Cubrinovski, M. \& Lo, S. R. (2012). Initial shear modulus of sandy soils and equivalent granular void ratio. Geomech. Geoengng 7, No. 3, 219-226.

Rahman, M. M., Lo, S. C. R. \& Dafalias, Y. F. (2014). Modelling the static liquefaction of sand with low-plasticity fines. Géotechnique 64, No. 11, 881-894, https://doi.org/10.1680/ geot.14.P.079.

Robertson, P. K., Woeller, D. I. \& Finn, W. D. L. (1992). Seismic cone penetration test for evaluating liquefaction potential under cyclic loading. Can. Geotech. J. 29, No. 4, 686-695.

Salgado, R., Bandini, P. \& Karim, A. (2000). Shear strength and stiffness of silty sand. J. Geotech. Geoenviron. Engng 126, No. 5, $451-462$.

Thevanayagam, S. (1998). Effect of fines and confining stress on undrained shear strength of silty sands. J. Geotech. Geoenviron. Engng 124, No. 6, 479-491.

Thevanayagam, S., Shenthan, T., Mohan, S. \& Liang, J. (2002). Undrained fragility of clean sands, silty sands, and sandy silts. J. Geotech. Geoenviron. Engng 128, No. 10, 849-859.

Verdugo, R. \& Ishihara, K. (1996). The steady state of sandy soils. Soils Found. 36, No. 2, 81-91.

Wood, D. M., Belkheir, K. \& Liu, D. F. (1994). Strain softening and state parameter for sand modelling. Géotechnique 44, No. 2, 335-339, https://doi.org/10.1680/geot.1994.44.2.335.

Yang, J. \& Li, X. S. (2004). State-dependent strength of sands from the perspective of unified modeling. J. Geotech. Geoenviron. Engng, ASCE 130, No. 2, 186-198.

Yang, J. \& Liu, X. (2016). Shear wave velocity and stiffness of sand: the role of non-plastic fines. Géotechnique 66, No. 6, 500-514, https://doi.org/10.1680/jgeot.15.P.205.

Yang, J. \& Wei, L. M. (2012). Collapse of loose sand with the addition of fines: the role of particle shape. Géotechnique 62, No. 12, 1111-1125, https://doi.org/10.1680/geot.11.P.062.

Yang, J., Wei, L. M. \& Dai, B. B. (2015). State variables for silty sands: global void ratio or skeleton void ratio? Soils Found. 55, No. 1, 99-111.

Yang, J., Liu, X., Guo, Y. \& Liang, L. B. (2017). A unified framework for evaluating in situ state of sand with varying fines content. Géotechnique, https://doi.org/10.1680/jgeot.16.P.254. 